\title{
How do surgeons decide to refer patients for adjuvant cancer treatment? Protocol for a qualitative study
}

Robin Urquhart ${ }^{1 *}$, Cynthia Kendell ${ }^{1}$, Joan Sargeant ${ }^{2,3}$, Gordon Buduhan $^{4}$, Paul Johnson $^{4}$, Daniel Rayson ${ }^{5}$, Eva Grunfeld ${ }^{6,7}$ and Geoffrey A Porter ${ }^{1,4,8}$

\begin{abstract}
Background: Non-small cell lung cancer, breast cancer, and colorectal cancer are commonly diagnosed cancers in Canada. Patients diagnosed with early-stage non-small cell lung, breast, or colorectal cancer represent potentially curable populations. For these patients, surgery is the primary mode of treatment, with (neo)adjuvant therapies (e.g., chemotherapy, radiotherapy) recommended according to disease stage. Data from our research in Nova Scotia, as well as others', demonstrate that a substantial proportion of non-small cell lung cancer and colorectal cancer patients, for whom practice guidelines recommend (neo)adjuvant therapy, are not referred for an oncologist consultation. Conversely, surveillance data and clinical experience suggest that breast cancer patients have much higher referral rates. Since surgery is the primary treatment, the surgeon plays a major role in referring patients to oncologists. Thus, an improved understanding of how surgeons make decisions related to oncology services is important to developing strategies to optimize referral rates. Few studies have examined decision making for (neo) adjuvant therapy from the perspective of the cancer surgeon. This study will use qualitative methods to examine decision-making processes related to referral to oncology services for individuals diagnosed with potentially curable non-small cell lung, breast, or colorectal cancer.

Methods: A qualitative study will be conducted, guided by the principles of grounded theory. The study design is informed by our ongoing research, as well as a model of access to health services. The method of data collection will be in-depth, semi structured interviews. We will attempt to recruit all lung, breast, and/or colorectal cancer surgeons in Nova Scotia $(n \approx 42)$, with the aim of interviewing a minimum of 34 surgeons. Interviews will be audiotaped and transcribed verbatim. Data will be collected and analyzed concurrently, with two investigators independently coding and analyzing the data. Analysis will involve an inductive, grounded approach using constant comparative analysis.

Discussion: The primary outcomes will be (1) identification of the patient, surgeon, institutional, and health-system factors that influence surgeons' decisions to refer non-small cell lung, breast, and colorectal cancer patients to oncology services when consideration for (neo)adjuvant therapy is recommended and (2) identification of potential strategies that could optimize referral to oncology for appropriate individuals.
\end{abstract}

Keywords: Cancer, Surgeon, Referral rates, Qualitative methods, Grounded theory

\footnotetext{
*Correspondence: robin.urquhart@cdha.nshealth.ca

${ }^{1}$ Cancer Outcomes Research Program, Cancer Care Nova Scotia, Halifax, Nova

Scotia, Canada

Full list of author information is available at the end of the article
}

\section{Biomed Central}

(c) 2012 Urquhart et al.; licensee BioMed Central Ltd. This is an Open Access article distributed under the terms of the Creative Commons Attribution License (http://creativecommons.org/licenses/by/2.0), which permits unrestricted use, distribution, and reproduction in any medium, provided the original work is properly cited. 


\section{Background}

Lung cancer, breast cancer (BC), and colorectal cancer (CRC) are extremely common in Canada. In 2011, it was estimated these three cancers accounted for $40 \%$ of all new cancer diagnoses nationally [1]. These three cancers also represent the leading cancer causes of death in Canada, accounting for $46 \%$ of all cancer deaths in 2011 [1]. In Nova Scotia (NS), the incidence rate of BC in females is similar to the national incidence rate, while the incidence rates for lung cancer and CRC are higher in NS for both males and females than national rates [1].

Cancer is a complex disease, often involving multiple healthcare providers from different clinical specialties. For patients with potentially curable disease, comprehensive care involves a sequence of events along a care trajectory that starts at a positive screen or first presentation of signs/symptoms to completion of all adjuvant therapies and ongoing surveillance. In regards to treatment, several distinct modalities may be used singly or in combination in an effort to achieve optimal patient outcomes (e.g., long-term survival). Patients diagnosed with early-stage non-small cell lung cancer (NSCLC), BC, or CRC represent potentially curable populations. For these individuals, surgical resection is the primary mode of potentially curative treatment, with (neo)adjuvant therapies provided according to clinical and/or pathological stage of disease.

Following surgical resection of the cancer, adjuvant therapies (e.g., chemotherapy, radiotherapy, hormonal therapy) may be recommended, depending on stage and evidence of benefit, to eradicate loco-regional or systemic microscopic residual disease. Without such therapy, the risk of recurrence with surgical resection alone may be high [2-4]. For some cancers, therapies may be recommended before the surgery in an effort to decrease tumor size ("downstage") and thus facilitate surgical resection, treat micrometastatic disease, and, in some situations, improve important patient-centered outcomes (e.g., morbidity). In such instances, the therapy is termed neoadjuvant, indicating it occurs prior to surgery, to distinguish it from adjuvant therapies in the postoperative period.

Unlike many malignancies (e.g., prostate cancer [5]), treatments for NSCLC, BC, and CRC are relatively standardized for the majority of patients receiving potentially curative resection. Indeed, large, randomized clinical trials have demonstrated that receipt of adjuvant chemotherapy improves overall survival in NSCLC, BC, and CRC patients with high-risk disease [6-13]. Consequently, clinical practice guidelines (CPGs), which provide syntheses of the best available evidence, recommend specific (neo)adjuvant therapies for patients with stage II/ IIIA NSCLC, stage I-III BC, stage II/III rectal cancer, and stage IIB/III colon cancer [14-19].

\section{Variations in treatment practices for potentially curable patients}

Despite clinical trials demonstrating clear efficacy, the impact of beneficial (neo)adjuvant therapies in patients diagnosed with cancer will ultimately depend on their uptake in patient populations outside of those trials [20]. Health-services research has consistently identified a gap between what is identified as "best practice" (as determined by scientific evidence, largely acquired via randomized clinical trials) and what actually happens in clinical care [21-27]. Many factors have been shown to influence awareness of, agreement with, adoption of, and adherence to best practices (i.e., CPGs). These include the needs and expectations of patients, characteristics of patients and providers, nature of the evidence and its mode of delivery, setting or context of care, and organizational and system constraints or enablers [2834]. Studies in Canada have revealed variations in (neo)adjuvant therapy rates for appropriate patients, with patient (e.g., age [20,22,27,35-39], comorbidities [36], place of residence $[35,37,40]$ ) and health-system (e.g., prevailing wait times $[40,41]$, centralized cancer services [42]) factors associated with these variations. The large variations by age, with older-aged individuals less likely to receive recommended care, demonstrate an age-specific bias toward no treatment, which is not necessarily supported by scientific evidence; in CRC, for example, advanced age has not been associated with lack of a survival benefit nor with increases in chemotherapy-induced toxicities $[10,43,44]$.

While CPGs are meant to guide decision making related to treatment options, and non-receipt of (neo)adjuvant therapy may be entirely appropriate given the circumstances of individual patients, one could argue that having a discussion (or "consultation") regarding the role of (neo)adjuvant therapy with a physician who specializes in (neo)adjuvant therapies represents the ideal management scenario for patients with potentially curable disease and in whom (neo)adjuvant therapy has been shown to be beneficial. Though there is no defined "ideal" benchmark for referral or consultation rates, both referral to and consultation with an oncologist have been identified as measures of quality care for patients with resected (or resectable) disease [45-47]. Canadian studies examining surgeon referral patterns at single tertiary care institutions report relatively low referral rates to oncology for resected NSCLC patients $[48,49]$ and large variations in referral patterns by patient characteristics for resected CRC patients [36].

Despite the existence of CPGs, clinicians from multiple specialties may have varying perspectives on the benefits/risks of cancer treatment, as well as different interpretations of an increasingly complex evidence base. Researchers have found that surgeons and oncologists 
report conflicting views on CPG recommendations for adjuvant therapies for $\mathrm{BC}$ [50] and CRC [51] patients, while preferred approaches for the management of NSCLC patients vary widely across and within medical and surgical specialties [52]. Thus, the extent to which various specialists become involved in patient care may affect patient decisions related to (neo)adjuvant therapies and the quality of care ultimately received. Referral to an oncologist has been identified as one of the key factors associated with receipt of chemotherapy [53-55].

\section{An assessment of referral and consultation rates in Nova Scotia}

In NS, we have comprehensively examined health-service utilization related to (neo)adjuvant therapy, including referral to an oncologist, oncologist consultation, and receipt of (neo)adjuvant therapy, for all patients diagnosed with CRC over a five-year time period [56]. Our findings revealed that a substantial proportion of patients for whom guidelines recommend consideration for (neo) adjuvant therapy, were not referred to the cancer center for a medical or radiation oncologist consultation. Specifically, we found that approximately one-third of resected stage II/III rectal cancer patients were not referred for a radiation oncology consultation (either in the neoadjuvant or adjuvant settings), and more than $20 \%$ of resected stage IIB/III colon cancer patients were not referred for a medical oncology consultation (unpublished data). Once referred, however, the vast majority of patients $(>97 \%)$ received the consultation. Furthermore, our populationbased research demonstrated that the most common reason for not receiving adjuvant chemotherapy in CRC patients for whom chemotherapy is recommended was not having a medical oncology consultation (representing $53 \%$ of patients who did not receive chemotherapy) [39]. While these findings may suggest an early selection of patients who were deemed not candidates for (neo)adjuvant therapy, they also point toward the need to better understand the patient, surgeon, institutional, and health-system factors that influence referral to oncology services in NS [39].

For NSCLC, Younis and colleagues [20] found that $73 \%$ of resected, stage II-III NSCLC patients in NS in 2005 received a referral to medical oncology for discussion of adjuvant chemotherapy. Crude data estimates from the Nova Scotia Cancer Registry suggest that referral rates for $\mathrm{BC}$ are higher than those for NSCLC and $\mathrm{CRC}$, with referral rates in six of nine health districts approaching or reaching 100\% (unpublished data). These data corroborate clinical experience, which suggests that surgeons in NS are more likely to refer BC patients to an oncologist for a discussion on the role of adjuvant therapy than NSCLC or CRC patients, despite the fact that many NS surgeons perform both BC and CRC surgery and thus appear to be acting differently for $\mathrm{BC}$ versus CRC patients. Taken together, these research and clinical observations reinforce the need to better understand the multiple factors that influence surgical decision making related to (neo)adjuvant therapies.

\section{Surgeon decision making with respect to cancer treatment(s)}

Since surgical resection represents the primary treatment for patients with potentially curative NSCLC, BC, and $\mathrm{CRC}$, the surgeon is chiefly responsible for referring patients to medical and/or radiation oncologists for discussions about (neo)adjuvant therapy. The surgeon also plays a role in the decision to offer (neo)adjuvant therapies (along with the oncologist) and to receive (neo)adjuvant therapies (along with the oncologist and patient). The decision to refer or to recommend therapy is not unlike other patient management decisions, which are invariably made in the midst of uncertainty as the surgeon considers factors such as the patient's risk of disease recurrence, life expectancy, comorbid conditions, and preferences, as well as information about the treatment and its potential benefits/costs. As such, surgeons may find themselves weighing the probability of clinical benefit versus potential or probable "costs" such as treatment toxicities, patient (non)compliance, patient difficulty accessing cancer treatment facilities, patient lodging and transportation expenditures associated with receiving care (which can represent significant out-of-pocket costs in Canada[57,58]), or even the human or financial resources expended (and possibly denied other patients). For example, population-based studies in the United States $[59,60]$ have demonstrated that a BC patient's distance to a radiotherapy facility is strongly associated with the type of surgery she receives (e.g., breast conservation versus mastectomy; radiotherapy is recommended following breast conservation surgery to reduce recurrence rates $[61,62])$, suggesting that the structure/centralization of cancer services does influence surgeons' decisions related to cancer treatment(s). Moreover, health-system factors shown to affect patient utilization of cancer services in Canada, such as prevailing wait times [40,41,63], may also influence surgeons' decisions to refer patients for a medical or radiation oncology consultation [64].

While population-based studies have demonstrated that variations in referral, consultation, and (neo)adjuvant therapy rates are associated with patient, provider, and healthsystem factors, the multiple factors that influence the process of decision making among cancer surgeons are not well understood. In Canada, research has been conducted into surgeon adoption of sentinel lymph node biopsy for $\mathrm{BC}$ and the factors influencing adoption. An initial survey of surgeons who treat BC across Canada found that, for the $39 \%$ of surgeon respondents who 
reported that they do not perform this procedure, the most commonly cited reasons were inadequate resources (53\%), lack of evidence to support the procedure (24\%), and lack of comfort with the technique (22\%) [65], suggesting that factors at multiple levels of the system (e.g., the evidence itself, the provider, and the institution) influence the decision to adopt this evidence-based practice. In a follow-up to this research, Wright and colleagues [66] conducted a qualitative study to gain a more in-depth understanding of the multiple factors that influence sentinel lymph node biopsy adoption. They found that the presence of a high-volume local surgical champion, interprofessional collaboration, institutional support, and the existence of internal hospital protocols and provincial-level CPGs all influenced surgeons' decisions to adopt this surgical procedure. In regards to decision making about (neo)adjuvant therapies, numerous researchers across Canada, all of whom have reported variations in referral rates and receipt of oncology services, have called for more in-depth study of referral and treatment patterns to improve our ability to develop more effective ways of optimizing care for patients with potentially curable disease $[27,36,39,67]$.

\section{Rationale for proposed study}

Worldwide, it has been estimated that one-third of cancer cases could be prevented and another one-third cured if practices consistently complied with CPGs [68]. In Canada, the Canadian Strategy for Cancer Control estimated that cancer outcomes could be improved by $30 \%$ with the appropriate application of existing evidence [69]. Receipt of (neo)adjuvant therapies for resected patients at high risk of recurrence is an essential component of this evidence. While a proportion of patients not referred to oncology services may be appropriately deemed poor candidates for (neo)adjuvant therapy, there may be other factors that influence the decision not to refer and thus prevent patients from receiving a medical or radiation oncologist consultation. Since surgeons act as the main "gatekeeper" to the organized cancer system, understanding how they make decisions related to oncology services is important to developing appropriate strategies and interventions to optimize referral rates and utilization of oncology services.

This study will use qualitative methods to examine decision-making processes related to referral to oncology services for individuals diagnosed with potentially curable NSCLC, BC, and CRC. These cancer sites were chosen for the following reasons:

1. High incidence [1]

2. Existence of clear, relatively standardized treatment practices for these diseases in the (neo)adjuvant setting, with evidence that adherence to best practices improves patient outcomes

3. For NSCLC and CRC, it has been demonstrated that a substantial minority of potentially curable patients in NS are not being referred for an oncology consultation $[20,39,56]$

4. Based on surveillance data and clinical experience, nearly all potentially curable stage I-III BC patients are referred for an oncology consultation in NS, even though most of the same surgeons are performing CRC surgeries, making $\mathrm{BC}$ a valuable and informative disease site to compare and contrast surgeon referral practices

Together, these reasons underscore the need for further study of referral decisions/behaviors in NS. Most researchers who study the adoption and implementation of best practices in healthcare emphasize the necessity of developing a good understanding of the influences on current practice in order to design more effective interventions $[30,31,70]$.

\section{Research objectives}

Through qualitative inquiry, surgeons will be asked to reflect on their decision-making processes related to referral to oncology services for potentially curable NSCLC, BC, and CRC patients, and on the specific factors that influence their decision to refer (or not). The primary objectives are to

1. Identify surgeons' perspectives on the patient, surgeon, institutional, and health-system factors that influence their decision to refer patients to oncology services;

i. Explore whether surgeons use a mental "threshold of benefit" schema for oncology services and, if so, how they weigh the benefits and costs of an oncology consultation/(neo)adjuvant therapy;

2. Identify the perceived barriers and enablers to referral to oncology services;

3. Explore whether the factors that influence decision making differ by disease site, specifically between patients diagnosed with $\mathrm{BC}$ versus patients diagnosed with NSCLC or CRC;

4. Identify potential strategies to promote referral to oncology services for patients for whom (neo) adjuvant therapy is recommended.

Related to objective 1 , we will attempt to identify whether and how patient (e.g., age, health status/comorbid conditions, preferences for care), surgeon (attitudes/ beliefs related to patients, awareness of evidence/CPGs 
for adjuvant therapies, level of specialization, and cancer surgery volume), institutional (e.g., academic versus community hospital, structures to facilitate collaborative decision making [e.g., access to multidisciplinary tumor boards], internal/hospital protocols), and health-system (e.g., availability of cancer system resources, accessibility of oncologists/cancer centers, availability/dissemination of provincial-level CPGs) factors influence surgeons' decision to refer patients to oncology services. Through qualitative inquiry, this study will seek to explore how surgeons evaluate the relative importance of these factors, or weigh the perceived benefits and costs, to come to a decision to refer (or not refer) their NSCLC, BC, or CRC patients for a medical or radiation oncology consultation.

\section{Conceptual framework}

This study is informed by our ongoing research in health services and implementation science [39,71-82], as well as an established model of access to health services [64]. Like all care providers, surgeons operate within a complex healthcare delivery system that is situated in a historical, social, economic, and political context. As a result, decisions related to (neo)adjuvant treatment are likely related to patient factors (e.g., functional status/ comorbidities, life expectancy, and risk of disease recurrence), surgeon factors (e.g., level of training/specialization, personal beliefs [52,83]), considerations of treatment benefits and risks, and the broader health system in which they operate. The Penchansky and Thomas [64] model of access to health services provides an approach to understanding access to healthcare that focuses on understanding the "fit" between a patient's needs and the system's ability to meet those needs. The model posits that "fit" can be measured through five dimensions, which relate to patient, provider, and health-system factors: availability (volume of physician and other healthcare resources), accessibility (geographic relationship between the users and providers of healthcare), accommodation (organization of care), affordability (costs of providing/receiving care), and acceptability (attitudes and characteristics of patients and providers). More recently, MacKillop [84] presented another important dimension of access: awareness of services and indications for their use. For example, a referring physician must be aware of indications for potentially beneficial services and that those services are available to the patient. Table 1 provides further detail on these six dimensions.

\section{Design and methods}

A qualitative research design using semi structured interviews will be used in this study. Qualitative data "document the world from the point of view of the people studied" (p. 165) [85], thereby providing insight
Table 1 Six dimensions related to access to health services

\begin{tabular}{|c|c|}
\hline Dimension & Examples \\
\hline Availability & $\begin{array}{l}\text { Resources (personnel, equipment, technology), } \\
\text { prevailing wait times }\end{array}$ \\
\hline Accessibility & $\begin{array}{l}\text { Centralized services, "close to home," transportation } \\
\text { difficulty }\end{array}$ \\
\hline Accommodation & $\begin{array}{l}\text { Coordination and integration of services, "satellite' } \\
\text { cancer clinics," telemedicine }\end{array}$ \\
\hline Affordability & $\begin{array}{l}\text { Funding of cancer services, insurance/drug coverage, } \\
\text { indirect patient costs (lodging, transportation) }\end{array}$ \\
\hline Acceptability & $\begin{array}{l}\text { Patient and provider attitudes toward one another, } \\
\text { patient characteristics (e.g., age, sex, comorbid } \\
\text { conditions, life expectancy), patient preferences, } \\
\text { provider characteristics (e.g., sex, years of practice, } \\
\text { level of specialization, surgery volume) }\end{array}$ \\
\hline Awareness & $\begin{array}{l}\text { Patient and provider awareness of evidence for } \\
\text { therapy, clinical practice guidelines, structures } \\
\text { that support multidisciplinary dialogue/consultation }\end{array}$ \\
\hline
\end{tabular}

into how people make sense of their experiences. Such insight cannot be easily provided by other methods [86]. Qualitative research is often used when there is little existing knowledge (or data) regarding the research topic and to help explain and/or interpret the results of quantitative research $[87,88]$.

\section{Methodology}

This qualitative study will be guided by the principles of grounded theory [89], which attempts to move beyond description and generate a general explanation (a "theory") of a process or action that is shaped by the views of participants who have experienced the process or action. Grounded theory is "grounded" in the sense that findings tend to be inductively derived from the data and the participants themselves.

According to the methods of grounded theory, concepts and categories are identified and developed as the research is being conducted [89]. While the emphasis of this methodology is on the inductive nature of theory building, Strauss and Corbin [89] do not object to the use of pre-existing theory per se, but rather in the way it might be used to influence the research process (e.g., by leading the researcher down a path of anticipated findings or assumptions). As Gerson [90] has demonstrated, a sophisticated grounded theory approach rejects the simplistic notion that theory building is entirely inductive (or deductive); instead, theory building occurs in an ongoing dialogue between pre-existing theory and new observations/insights generated from empirical research.

\section{Semi structured interviews}

In-depth, semi structured interviews will be conducted with NS thoracic, breast, and colorectal surgeons to gain 
their perspectives on factors that influence their decisions to refer patients to oncology services. The value of interviewing is that we can discover understanding about people and their actions that cannot be observed: "[w]e cannot observe how people have organized the world and the meanings they attach to what goes on in the world. We have to ask people questions about those things" (p. 341) [87]. The semi structured interviews will be face-to-face or telephone interviews depending upon practical considerations, such as travel distance to interview a limited number of participants.

Open-ended questions and related probes will be drafted based on the research objectives, team members' clinical experiences, and the Penchanksy and Thomas model [64], with the latter providing further insight into the patient, surgeon, institutional, and health-system factors influencing utilization of health services. Since decisions around not to refer/treat are made in the context of individual patients, the script will also include scenario-like questions to explore, in a more in-depth manner, how surgeons consider (or weigh) various factors (e.g., relative survival benefit, comorbidities). Interview questions will be adapted for thoracic, breast, and colorectal surgeons since NSCLC, BC, and CRC are different diseases that require different treatment approaches, each with varying degrees of relative benefit. Collectively, the questions will seek to understand how surgeons experience the process of deciding to refer patients for oncology consultation and to identify the factors that influence this process. Two pilot interviews will be conducted with surgeons not part of the research team. These will be audiotaped, transcribed verbatim, and discussed amongst the entire research team to ensure that all topics of interest are explored. The interview script will be refined through these pilot interviews. Consistent with grounded theory principles, the interview guide will be employed in a formative manner and adapted during data collection on the basis of previous interview findings to further explore important concepts and emerging categories [87,91].

One investigator [RU], who is experienced in qualitative methods, will carry out all interviews.

At the beginning of each interview, descriptive information related to the surgeon (e.g., years of practice, level of specialization, cancer surgery volume) and institution (e.g., presence of internal/ hospital protocols, access to multidisciplinary tumor boards) will be collected using a standardized data collection form. Regardless of interviewing mode (face-to-face or telephone), the interviews will be open and characterized by a personal approach, meaning that the interviewer will have a prior understanding of the background and work of the participants, ensure that the participants clearly understand the study objectives and interview procedure, and encourage the participants to express their opinions by explaining that all answers are valid/valuable and will be included in the analysis. Our experience is that such an approach results in encounters that are more like conversations than structured interviews with a series of fixed questions [88]. All interviews will be audiotaped to ensure the data are captured and retrievable in true form and transcribed verbatim by a research coordinator with experience in transcription. The audiotapes and transcripts will be supplemented with field notes (or memos), allowing the interviewer to highlight particularly insightful data and to capture personal reflections during data collection. Transcripts will be verified by listening to the audiotapes. Following each interview, the questions and responses will be reviewed to determine whether or not the issues were answered in sufficient depth and, if not, to revise the questions before the next interview [91].

\section{Study participants}

In grounded theory, the point is to gather enough data to fully develop (or saturate) the explanation [89]. Since there are only a limited number of surgeons in NS who perform NSCLC, BC, and/or CRC surgery $(n \approx 42)$, we will attempt to recruit all of these surgeons for this study. We will include the data from the pilot interviews with all interview data, with pilot participants' permission. Recruiting all surgeons will provide a sample with differences in career stage (junior, senior), level of training (general surgeon, surgical oncologist), and practice location (community hospital, academic/tertiary care center). Recognizing that not all surgeons may agree to participate, we aim to interview a minimum of 34 surgeons (80\% of relevant surgeons). Our prior experiences surveying rectal cancer surgeons [92] and interviewing breast and colorectal surgeons [unpublished data] in NS suggest this participation rate is achievable.

While recruitment in grounded theory is based on theoretical sampling and saturation, we will attempt to recruit all surgeons due to the relatively small number of surgeons in NS who perform these surgeries. Nonetheless, we will discontinue data collection if we reach saturation before all surgeons are asked to participate. When/if we determine we are nearing theoretical saturation, but some categories (or properties of categories) require further examination, we will make strategic decisions about who will provide the most informationrich source of data to meet our analytic needs (i.e., theoretical sampling).

\section{Recruitment methods}

Two investigators [RU, GAP] will identify all potential participants and initially approach each potential participant in person or via email or telephone to briefly 
introduce the study and ask whether he/she is willing to participate. If the participant responds in the affirmative, a research coordinator will follow up with the participant to discuss in detail the nature and purpose of the study and to arrange for a time to conduct the informed consent discussion and interview. If a potential participant fails to respond to the initial contact within one week, an investigator [GAP or RU] will follow up with him/her via telephone.

\section{Anticipated ethical issues}

The study poses no serious ethical problems. Ethical approval to conduct this study has been obtained from Capital District Health Authority. Written informed consent will be obtained from each participant. This will include permission to audiotape the sessions and to use anonymized quotes. Any publication will not attribute specific comments to identifiable participants. Participants' geographic locations (e.g., health region) will not be identified; rather, participants will be described as practicing in community or academic settings.

\section{Analysis}

Data will be collected and analyzed concurrently, allowing emergent concepts and categories to be incorporated and explored in subsequent interviews. An inductive, grounded approach, using constant comparative analysis, will be used for qualitative analysis of interview transcripts and field notes [89]. Grounded theory analysis involves coding; constant comparison; and identification, organization, and refinement of categories. Specifically, the analytic process will entail reading and rereading of transcripts, development of a coding scheme reflecting unique ideas and concepts, application of the coding scheme to the interview text, and grouping of coded text into categories relevant to the study objectives.

Identifying codes is a critical component of the data analysis stage. Coding is defined as the process of grouping participants' responses into categories that bring together similar ideas, concepts, or themes that the researcher has discovered through familiarity with the interviews and text [91]. Code words reflect the essence of the data and lead to ease of recognition as the number of coded words increase. Consistent with constant comparative analysis, open and axial coding of interview transcripts will occur simultaneously. Open coding entails reading the transcribed interviews line by line in their entirety to identify ideas and concepts and then grouping concepts to form categories and subcategories. This process also involves routinely revisiting previous codes for refining purposes.

Axial coding is used to make connections between the categories and subcategories of codes. Repeating ideas are brought together, leading to the reduction and clustering of categories based on content similarity. These categories will be reviewed and refined based on their relationship to one another and their ability to explain the factors that influence decision-making processes related to referral to oncology services for NSCLC, BC, and CRC. This process will involve ongoing review of the emerging analysis to determine whether and how to expand or merge categories, which will help to ensure that they are reflective of the interview data.

The final stage of analysis will be selective coding, or the detailed development of categories, selection of a core theoretical category, and integration of categories. Specifically, Strauss and Corbin [89] describe selective coding as "the process of selecting the central or core category, systematically relating it to other categories, validating those relationships, and filling in categories that need further refinement and development" (p. 116). The core category should have the analytic strength to "pull the other categories together to form an explanatory whole" (p. 146). However, it must be noted that, for selective coding, theoretical saturation should be reached. Therefore, the analytic process may be limited if we have interviewed all relevant, participating surgeons but have not reached saturation. Nonetheless, identification of categories, linking of categories and subcategories, and clustering around a core or central concept will help us develop a theory (or the building blocks of a theory) that deepens understanding and facilitates action in this important clinical area.

Data will be coded and analyzed independently by two investigators [RU, CK]. These investigators will develop an electronic codebook to guide the coding scheme and subsequent categorization of data; this will be achieved through iterative discussion throughout the data analysis process. The codebook will contain code definitions, sample data illustrating application of the code, and decision rules related to each code. Qualitative analysis will be performed manually, with the assistance of qualitative software (NVivo; QSR International, Cambridge, MA, USA) for data management and to enable comparison and synthesis of codes. To improve the reliability of findings, a third investigator [JS] will review the codebook, all analytic decisions, and sample transcripts or sections of transcripts. We will resolve disagreement among investigators through discussion and, when needed, reexamining transcripts and coded data. To ensure consistency and authenticity of the entire qualitative process, preliminary findings will also be discussed with the three members of the research team who are practicing cancer surgeons in NSCLC, BC, and CRC [GAP, PJ, GB]. The final categories will be presented in diagrams to visually represent the conceptual relationship among categories, tabular form to address each 
objective, and discussed in relation to the local context as well as the broader scientific literature.

\section{Strategies for increasing rigor}

Numerous steps consistent with qualitative research will be taken to ensure the overall rigor of the proposed study. These include field journal/note-taking during interviews; detailed documentation of methodological and analytic decisions (i.e., an audit trail) to clearly illustrate the means of arriving at the codes and findings and to avoid overgeneralization and unsubstantiated conclusions; systematic data coding and analysis; use of direct quotations to ensure the perspectives of the participants are represented as clearly as possible and to provide the reader with a clearer sense of the evidence on which the findings and interpretations are based; member checking by sending interview participants a summary of the main findings extracted from their interview; review of the data coding process, analytic decisions, and resultant themes by three investigators [RU, CK, JS]; and review and in-person discussion of preliminary findings by three investigators who are practicing cancer surgeons [GAP, PJ, GB]. Importantly, triangulation of findings by the research team and high levels of team involvement throughout data analysis and interpretation enhance rigor by minimizing the chance that important thematic ideas go unnoticed and helping to ensure that the organization of data and the resulting conclusions are transparent.

\section{Discussion}

The primary outcomes of this study will be (1) identification of the patient, surgeon, institutional, and healthsystem factors that influence surgeons' decisions to refer NSCLC, BC, and CRC patients to oncology services when consideration for (neo)adjuvant therapy is recommended and (2) identification of potential strategies (interventions) that could increase referral to oncology for appropriate individuals. The findings from this study will help fill an important gap in our understanding of how surgeons make decisions in regards to their patients and how (and the extent to which) organizational and health-system factors can influence decision making during the clinical encounter. As such, the knowledge gained will support the development and implementation of appropriate strategies to optimize referral rates and access to oncology services. Depending on the surgeon-identified influential factors, strategies could target the patient level (e.g., patient decision aids, shared decision-making models), surgeon level (e.g., focused educational activities, audit and feedback), and/or organizational/policy level (e.g., performance monitoring systems, expansion of multidisciplinary tumor boards, use of telemedicine) of the health system. For example, expansion of multidisciplinary tumor boards across the province, or introduction of telemedicine services to permit "just-in-time" surgeon and/or patient consultation with an oncologist at a cancer center, may increase collaborative decision making and optimize referrals to oncology services [39], and support co-management options for community-based surgeons who do not have regular opportunities to interact with other cancer specialists [93].

In summary, receipt of (neo)adjuvant therapies for appropriate patients is an essential component of evidence-based practice for NSCLC, BC, and CRC patients. In NS, prior research indicates that a substantial proportion of NSCLC and CRC patients for whom CPGs recommend consideration for (neo)adjuvant therapy are not referred for a medical or radiation oncologist consultation. Since surgeons act as a "gatekeeper" to the organized cancer system, understanding how they make decisions related to oncology services is important to developing appropriate strategies and interventions to optimize referral rates and improve access to these services.

\section{Competing interests \\ The authors have no conflicts of interest to declare.}

\section{Authors' contributions}

$\mathrm{RU}$ and GAP conceived the idea for this study, led the intellectual development and protocol writing, and will be primarily responsible for its conduct. CK, JS, GB, PJ, DR, and EG all contributed to the drafting and development of the study. All authors read and approved the final manuscript.

\section{Acknowledgments}

This study is funded by an operating grant from the Canadian Institutes of Health Research. The funding body has no role in the design, collection, analysis, and interpretation of data; in the writing of the manuscript; or in the decision to submit the manuscript for publication.

\section{Author details}

${ }^{1}$ Cancer Outcomes Research Program, Cancer Care Nova Scotia, Halifax, Nova Scotia, Canada. ${ }^{2}$ Division of Medical Education, Dalhousie University, Halifax, Nova Scotia, Canada. ${ }^{3}$ Continuing Medical Education, Dalhousie University, Halifax, Nova Scotia, Canada. ${ }^{4}$ Department of Surgery, Dalhousie University, Halifax, Nova Scotia, Canada. ${ }^{5}$ Division of Medical Oncology, Dalhousie University, Halifax, Nova Scotia, Canada. ${ }^{6}$ Ontario Institute for Cancer Research, Toronto, Ontario, Canada. ${ }^{7}$ Department of Family and Community Medicine, University of Toronto, Toronto, Ontario, Canada. ${ }^{8}$ Department of Community Health and Epidemiology, Dalhousie University, Halifax, Nova Scotia, Canada.

Received: 22 September 2012 Accepted: 22 October 2012 Published: 25 October 2012

\section{References}

1. Canadian Cancer Society's Steering Committee: Canadian Cancer Statistics 2011. Toronto, ON: Canadian Cancer Society; 2011.

2. NIH consensus conference. Adjuvant therapy for patients with colon and rectal cancer. JAMA 1990, 264(11):1444-1450.

3. Figueredo A, Germond C, Taylor B, Maroun J, Agboola O, Wong R, Zwaal C, Miccucci S, for the Gastrointestinal Cancer Disease Site Group: Postoperative adjuvant radiotherapy or chemotherapy for resected stage II or III rectal cancer. Curr Oncol 2000, 7:37-51.

4. Fisher B, Anderson S, Redmond CK, Wolmark N, Wickerham DL, Cronin WM: Reanalysis and results after 12 years of follow-up in a randomized clinical trial comparing total mastectomy with lumpectomy with or 
without irradiation in the treatment of breast cancer. N Engl J Med 1995, 333(22):1456-1461.

5. Birnie K, Robinson J: Helping patients with localized prostate cancer reach treatment decisions. Can Fam Phys 2010, 56(2):137-141.

6. Arriagada R, Bergman B, Dunant A, Le Chevalier T, Pignon JP, Vansteenkiste J, International Adjuvant Lung Trial Collaborative Group: Cisplatin-based adjuvant chemotherapy in patients with completely resected non-smallcell lung cancer. N Engl J Med 2004, 350(4):351-360.

7. Douillard JY, Rosell R, De Lena M, Carpagnano F, Ramlau R, Gonzales-Larriba JL, Grodzki T, Pereira JR, Le Groumellec A, Lorusso V, et al: Adjuvant vinorelbine plus cisplatin versus observation in patients with completely resected stage IB-IIIA non-small-cell lung cancer cancer (Adjuvant Navelbine International Trialist Association [ANITA]): a randomised controlled trial. Lancet Oncol 2006, 7(9):719-727.

8. Early Breast Cancer Trialists' Collaborative Group: Effects of chemotherapy and hormonal therapy for early breast cancer on recurrence and 15-year survival: an overview of the randomised trials. Lancet 2005, 365(9472):1687-1717.

9. QUASAR Collaborative Group, Gray R, Barnwell J, McConkey C, Hills RK, Williams NS, Kerr DJ: Adjuvant chemotherapy versus observation in patients with colorectal cancer: a randomised study. Lancet 2007 , 370(9604):2020-2029.

10. Sargent DJ, Goldberg RM, Jacobson SD, Macdonald JS, Labianca R, Haller DG, Shepherd LE, Seitz JF, Francini G: A pooled analysis of adjuvant chemotherapy for resected colon cancer in elderly patients. N Engl J Med 2001, 345(15):1091-1097

11. Strauss GM, Herndon J, Maddaus MA, Johnstone DW, Johnson EA, Watson DJ, Sugarbaker DJ, Schilsky RL, Green MR: Randomized clinical trial of adjuvant chemotherapy with paclitaxel and carboplatin following resection in Stage IB non-small cell lung cancer (NSCLC): Report of Cancer and Leukemia Group B (CALGB) Protocol 9633. J Clin Oncol 2004, 22(14S):A7019.

12. Winton $T$, Livington $R$, Johnson $D$, Rigas J, Johnston M, Butts $C$, Cormier $Y$, Goss $G$, Inculet R, Vallieres $E$, et al: Vinorelbine plus cisplatin vs. observation in resected non-small-cell lung cancer. N Engl J Med 2005, 352(25):2589-2597.

13. Wolpin BM, Meyerhardt JA, Mamon HJ, Mayer RJ: Adjuvant treatment of colorectal cancer. CA Cancer J Clin 2007, 57(3):168-185.

14. Cancer Care Ontario: Breast Cancer Evidence-based Series (EBS) and Practice Guidelines (PG). 2012. Available at: https://www.cancercare.on.ca/toolbox/ qualityguidelines/diseasesite/breast-ebs/.

15. Cancer Care Ontario: Gastrointestinal Cancer Evidence-based Series (EBS) and Practice Guidelines (PG). 2012. Available at: https://www.cancercare.on.ca/ cms/One.aspx?portalld=1377\&pageld=10207.

16. Cancer Care Ontario: Lung Cancer Evidence-based Series (EBS) and Practice Guidelines (PG). 2012. Available at: https://www.cancercare.on.ca/toolbox/ qualityguidelines/diseasesite/lung-ebs/.

17. Figueredo A, Fine S, Maroun J, Walker-Dilks C, Wong S: Adjuvant therapy for stage III colon cancer after complete resection. Provincial Gastrointestinal Disease Site Group. Cancer Prev Control 1997, 1(4):314-319.

18. Pisters KM, Evans WK, Azzoli CG, Kris MG, Smith CA, Desch CE, Somerfield MR, Brouwers MC, Darling G, Ellis PM, et al: Cancer Care Ontario and American Society of Clinical Oncology adjuvant chemotherapy and adjuvant radiation therapy for stages I-IIIA resectable non small-cell lung cancer guideline. J Clin Oncol 2007, 25(34):5506-5518.

19. Wong R, Berry S, Spithoff K, Simunovic M, Chan K, Agboola O, Dingle B, Rumble RB, Cummings B, Gastrointestinal Cancer Disease Site Group: Preoperative or Postoperative Therapy for the Management of Patients with Stage II or III Rectal Cancer: Guideline Recommendations. Hamilton, ON: Program in Evidence-Base Care, Cancer Care Ontario; 2008.

20. Younis T, Al-Fayea T, Virik K, Saint-Jacques N: Adjuvant chemotherapy uptake in non-small cell lung cancer. $J$ Thor Oncol 2008, 3(11):1272-1278.

21. Brown LC, Johnson JA, Majumdar SR, Tsuyuki RT, McAlister FA: Evidence of suboptimal management of cardiovascular risk in patients with type 2 diabetes mellitus and symptomatic atherosclerosis. CMAJ 2004, 1717(10):1189-1192.

22. Cree M, Tonita J, Turner D, Nugent Z, Alvi R, Barss R, King C, Winget M: Comparison of treatment received versus long-standing guidelines for stage III colon and stage II/III rectal cancer patients diagnosed in
Alberta, Saskatchewan, and Manitoba in 2004. Clin Colorectal Cancer 2009, 8(3):141-145

23. Francke AL, Smith MC, de Veer AJ, Mistiaen P: Factors influencing the implementation of clinical guidelines for health care professionals: a systematic meta-review. BMC Med Inform Dec Mak 2008, 8:38.

24. Grunfeld E, Hodgson DC, Del Giudice E, Moineddin R: Population-based longitudinal study of follow-up care for breast cancer survivors. J Oncol Practice 2010, 6(4):174-181.

25. Latosinsky S, Fradette K, Lix L, Hildebrand K, Turner D: Canadian breast cancer guidelines: have they made a difference? CMAJ 2007, 176(6):771-776.

26. McGlynn EA, Asch SM, Adams J, Keesey J, Hicks J, DeCristofaro A, Kerr EA The quality of health care delivered to adults in the United States. N Engl J Med 2003, 348(26):2635-2645.

27. Winget $M$, Hossain S, Yasui $Y$, Scarfe A: Characteristics of patients with stage III colon adenocarcinoma who fail to receive guidelinerecommended treatment. Cancer 2010, 116(20):4849-4856.

28. Contandriopoulos D, Lemire M, Denis JL, Tremblay E: Knowledge exchange processes in organizations and policy arenas: a narrative systematic review of the literature. Milbank Q 2010, 88(4):444-483.

29. Davis D, Evans M, Jadad A, Perrier L, Rath D, Ryan D, Sibbald G, Straus S, Rappolt S, Wowk M, et al: The case for knowledge translation: shortening the journey from evidence to effect. BMJ 2003, 327(7405):33-35.

30. Grol R, Bosch MC, Hulscher M, Eccles MP, Wensing M: Planning and studying improvement in patient care: the use of theoretical perspectives. Milbank Q 2007, 85(1):93-138.

31. Grol R, Grimshaw J: From best evidence to best practice: effective implementation of change in patients' care. Lancet 2003, 362(9391):1225-1230.

32. Iles V, Sutherland K: Organizational change: A review for health care managers, professionals and researchers. London, UK: National Health Service; 2001. Available at: http://www.sdo.nihr.ac.uk/files/adhoc/ change-management-review.pdf.

33. Kitson AL: The need for systems change: reflections on knowledge translation and organizational change. J Adv Nurs 2009, 65(1):217-228.

34. Kitson AL, Rycroft-Malone J, Harvey G, McCormack B, Seers K, Titchen A: Evaluating the successful implementation of evidence into practice using the PARiHS framework: theoretical and practical challenges. Implement Sci 2008, 3(1):1.

35. Kerba M, Miao Q, Zhang-Salomons J, Mackillop WJ: Defining the need for breast cancer radiotherapy in the general population: a criterion-based benchmarking approach. Clin Oncol (R Coll Radiol) 2007, 19(7):481-489.

36. Ong S, Watters JM, Grunfeld E, O'Rourke K: Predictors of referral for adjuvant therapy for colorectal cancer. Can J Surg 2005, 48(3):225-229.

37. Paszat LF, Groome PA, Mackillop WJ, Zhang-Salomons J, Schulze K, Holowaty E: Radiotherapy for breast cancer in Ontario: rate variation associated with region, age and income. Clin Invest Med 1998, 21(3):125-134

38. Tyldesley S, Zhang-Salomons J, Groome PA, Zhou S, Schulze K, Paszat LF, Mackillop WJ: Association between age and the utilization of radiotherapy in Ontario. Int J Radiol Oncol Biol Phys 2000, 47(2):469-480.

39. Rayson D, Urquhart R, Cox M, Grunfeld E, Porter G: Adherence to clinical practice guidelines for adjuvant chemotherapy for colorectal cancer in a Canadian province: a population-based analysis. J Oncol Pract 2012, 8(4):253-259.

40. Hanna TP: A population-based study of factors affecting access to radiotherapy for endometrial cancer in Ontario. Department of Community Health and Epidemiology: Queens University; 2009.

41. Zhang-Salomons J, Fourodi F, Huang J, Mackillop WJ: Health system effects on the use of radiotherapy following surgery for breast cancer. Abstr Acad Health Serv Res Health Policy Meet 2002, 19:45.

42. Mackillop WJ, Groome PA, Zhang-Salomons JY, Zhou Y, Feldman-Stewart D, Paszat LF, Dixon P, Holowaty EJ, Cummings BJ: Does a centralized radiotherapy system provide adequate access to care? J Clin Oncol 1997, 15(3):1261-1271.

43. Goldberg RM, Tabah-Fisch I, Bleiberg H, de Gramont A, Tournigand C, Andre T, Rothenberg ML, Green E, Sargent DJ: Pooled analysis of safety and efficacy of oxaliplatin plus fluorouracil/leucovorin administered bimonthly in elderly patients with colorectal cancer. J Clin Oncol 2006 24(25):4085-4091. 


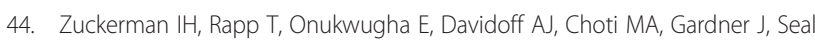
$B$, Mullins CD: Effect of age on survival benefit of adjuvant chemotherapy in elderly patients with Stage III colon cancer. J Am Geriatr Soc 2009, 57(8):1403-1410.

45. Gagliardi A, Wright FC, Quan ML, McCready D: Evaluating the organization and delivery of breast cancer services: use of performance measures to identify knowledge gaps. Breast Cancer Res Treat 2007, 103(2):131-148.

46. Gagliardi AR, Simunovic M, Langer B, Stern H, Brown AD: Development of quality indicators for colorectal cancer surgery, using a 3-step modified Delphi approach. Can J Surg 2005, 48(6):441-452.

47. McGory ML, Shekelle PG, Yo CY: Development of quality indicators for patients undergoing colorectal cancer surgery. J Natl Cancer Inst 2006, 98(22):1623-1633.

48. Bouchard N, Laberge F, Raby B, Martin S, Lacasse Y: Adjuvant chemotherapy in resected lung cancer: two-year experience in a university hospital. Can Respir J 2008, 15(5):270-274.

49. Kassam F, Shepherd FA, Johnston M, Visbal A, Feld R, Darling G, Keshavjee S, Pierre A, Waddell T, Leighi NB: Referral patterns for adjuvant chemotherapy in patients with completely resected non-small cell lung cancer. J Thorac Oncol 2007, 2(1):39-43.

50. Jagsi R, Abrahamse P, Morrow M, Hamilton AS, Graff JJ, Katz SJ: Coordination of Breast Cancer Care Between Radiation Oncologists and Surgeons: A Survey Study. Int J Radiat Oncol Biol Phys 2012, 82(5):2072-2078

51. Keating NL, Landrum MB, Klabunde CN, Fletcher RH, Rogers SO Jr, Doucette WR, Tisnado D: Adjuvant chemotherapy for stage III colon cancer: do physicians agree about the importance of patient age and comorbidity? J Clin Oncol 2008, 26(15):2532-2537.

52. Schroen AT, Detterbeck FC, Crawford R, Rivera MP, Socinski MA: Beliefs among pulmonologists and thoracic surgeons in the therapeutic approach to non-small cell lung cancer. Chest 2000, 118(1):129-137.

53. Davidoff AJ, Rapp T, Onukwugha E, Zuckerman $I H$, Hanna N, Pandya N, Mullins CD: Trends in disparities in receipt of adjuvant therapy for elderly stage III colon cancer patients, the role of the medical oncologist evaluation. Med Care 2009, 47(12):1229-1236.

54. Luo R, Giordano SH, Freeman JL, Zhang DD, Goodwin JS: Referral to medical oncology: a crucial step in the treatment of older patients with stage III colon cancer. Oncologist 2006, 11(9):1025-1033.

55. Luo R, Giordano SH, Zhang DD, Freeman J, Goodwin JS: The role of the surgeon in whether patients with lymph node-positive colon cancer see a medical oncologist. Cancer 2007, 109(5):975-982.

56. Grunfeld E, Porter GA, Rayson D, Johnston G, Burge F, van Zanten S, Kisely S, Kephart G, Dewar R, Rheaume D, et al: Towards measuring and improving access to quality cancer services in Nova Scotia. Halifax, NS: Canadian Institutes of Health Research (CIHR); 2007-2012.

57. Dunscombe P, Roberts $G$ : Radiotherapy service delivery models for a dispersed patient population. Clin Oncol (R Coll Radiol) 2001, 13(1):29-37.

58. Matthews M, Basky G: Closer to home: the burden of out-of-pocket expenses on cancer patients in Newfoundland and Labrador. St. John's, NL: Memorial University of Newfoundland; 2004.

59. Nattinger $A B$, Kneusel RT, Hoffmann RG, Gilligan MA: Relationship of distance from a radiotherapy facility and initial breast cancer treatment. J Natl Cancer Inst 2001, 93(17):1344-1346.

60. Schroen AT, Brenin DR, Kelly MD, Knaus WA, Slingluff CL Jr: Impact of patient distance to radiation therapy on mastectomy use in early-stage breast cancer patients. J Clin Oncol 2005, 23(28):7074-7080.

61. Lazovich D, Solomon CC, Thomas DB, Moe RE, White E: Breast conservation therapy in the United States following the 1990 National Institutes of Health Consensus Development Conference on the treatment of patients with early stage invasive breast carcinoma. Cancer 1999, 86(4):628-637

62. Whelan TJ, Lada BM, Laukkanen E, Perera FE, Shelley WE, Levine MN: Breast irradiation in women with early stage invasive breast cancer following breast conservation surgery. Provincial Breast Disease Site Group. Cancer Prev Control 1997, 1(3):228-240.

63. Kong W, Zhang-Salomons J, Hanna TP, Mackillop WJ: A population-based study of the fractionation of palliative radiotherapy for bone metastasis in Ontario. Int J Radiat Oncol Biol Phys 2007, 69(4):1209-1217.

64. Penchansky R, Thomas JW: The concept of access: definition and relationship to consumer satisfaction. Med Care 1981, 19(2):127-140.
65. Quan ML, Hodgson N, Lovrics P, Porter GA, Poirier B, Wright FC: National adoption of sentinel node biopsy for breast cancer: lessons learned from the Canadian experience. Breast J 2008, 14(5):421-427.

66. Wright FC, Gagliardi AR, Fraser N, Quan ML: Adoption of surgical innovations: factors influencing use of sentinel lymph node biopsy for breast cancer. Surg Innov 2011, 18(4):379-386.

67. Winget $M$, Stanger T, Gao Z, Butts C: Predictors of surgery and consult with an oncologist for adjuvant chemotherapy in early stage NSCLC patients in Alberta, Canada. J Thorac Oncol 2009, 4(5):629-634.

68. World Health Organization: Bridging the "know-do" gap. Meeting on knowledge translation in global health. Geneva, Switzerland: World Health Organization; 2006.

69. Canadian Cancer Control Strategy: Canadian Strategy for Cancer Control. Draft Synthesis Report. Ottawa, ON: Canadian Cancer Control Strategy; 2001.

70. Graham ID, Logan J, Harrison MB, Straus SE, Tetroe J, Caswell W, Robinson $\mathrm{N}$ : Lost in knowledge translation: time for a map? J Contin Educ Health Prof 2006, 26(1):13-24

71. Porter GA, Urquhart R, Bu J, Johnson PJ, Grunfeld E: Improving nodal harvest in colorectal cancer: So What? Ann Surg Oncol 2011, 18(1):S35.

72. Porter GA, Urquhart R, Bu J, McConnell YJ, Grunfeld E: Timely access and quality of care in colorectal cancer: A population-based analysis. Ann Surg Oncol 2010, 17(Suppl 1):S118.

73. Urquhart R, Bu J, Porter GA, Dewar R, Moineddin R, Grunfeld E: Relationship between survival and lymph node assessment from a population-based study of colorectal cancer patients. J Clin Oncol 2010, 28(15).

74. Urquhart R, Grunfeld E: Building tools to measure and improve access to and quality of colorectal cancer care in Nova Scota. Can J Gastroenterol 2010, 24(Suppl A):91A

75. Urquhart R, Grunfeld E, Porter GA: Synoptic reporting and the quality of cancer care: a review of evidence and Canadian initiatives. Oncology Exchange 2009, 8(1):28-31.

76. Johnson PM, Malatjalian D, Porter GA: Adequacy of nodal harvest in colorectal cancer: a consecutive cohort study. J Gastrointest Surg 2002, 6(6):883-888.

77. Johnson PM, Porter GA, Ricciardi R, Baxter NN: Increasing negative lymph node count is independently associated with improved long-term survival in stage IIIB and IIIC colon cancer. J Clin Oncol 2006, 24(22):3570-3575.

78. Folkes A, Urquhart R, Zitzelsberger L, Grunfeld E: Breast cancer guidlelines in Canada: a review of development and implementation. Breast Care (Basel) 2008, 3(2):108-113.

79. Grunfeld E, Zitzelsberger L, Hayter C, Berman N, Cameron R, Evans WK, Stern $\mathrm{H}$ : The role of knowledge translation for cancer control in Canada. Chron Dis Can 2004, 25(2):1-6.

80. Daigle R, Urquhart R, Cox M, Grunfeld E, Porter GA: A population-based study of emergency room presentation in colorectal cancer. Can J Surg 2010, 53(4):S65-S66. Canadian Surgery Forum meeting abstracts.

81. Urquhart R, Folkes A, Porter G, Kendell C, Cox M, Dewar R, Grunfeld E: Population-based longitudinal study of follow-up care for colorectal cancer patients in Nova Scotia. J Oncol Pract 2012, 8(4):246-252.

82. Urquhart R, Porter $G$, Grunfeld E: Reflections on knowledge brokering within a multidisciplinary research team. J Contin Educ Health Prof 2011, 31(4):283-290.

83. Raby B, Pater J, Mackillop WJ: Does knowledge guide practice? Another look at the management of non-small-cell lung cancer. J Clin Oncol 1995, 13(8):1904-1911.

84. Mackillop WJ: Health services research in radiation oncology: Towards achieving the cchievable for patients with cancer. In Clinical Radiation Oncology. 2nd edition. Edited by Gunderson LL, Tepper JE. Philadelphia, PA: Churchill Livingstone; 2006.

85. Hammersley M: What's wrong with ethnography?: methodological explorations. London: Routledge; 1992.

86. Rice PL: In quality we trust!: the role of qualitative data in health care. Med Principles and Practice 1996, 5:51-57.

87. Patton MQ: Qualitative research \& evaluation methods. 3rd edition. Thousand Oaks, CA: SAGE Publications; 2002

88. Rice PL, Ezzy D: Qualitative research methods: a health focus. Oxford: Oxford University Press; 1999.

89. Strauss AL, Corbin JM: Basics of qualitative research: grounded theory procedures and techniques. Thousand Oaks, CA: Sage; 1990. 
90. Gerson E: Supplementing grounded theory. In Social Organization and Social Process. Edited by Maines D. New York: Aldine de Gruyter; 1991.

91. Rubin H, Rubin I: Qualitative interviewing: the art of hearing data. Thousand Oaks, CA: Sage Publications; 1995.

92. Richardson DP, Porter GA, Johnson PM: Surgeon knowledge is associated with clinical and oncologic outcomes in patients with rectal cancer. Ann Surg Oncol 2011, 18(Suppl 1):S102.

93. Rogers SO Jr, Ayanian JZ, Ko CY, Kahn KL, Zaslavsky AM, Sandler RS, Keating $\mathrm{NL}$ : Surgeons' volume of colorectal cancer procedures and collaborative decision-making about adjuvant therapies. Ann Surg 2009, 250(6):895-900.

doi:10.1186/1748-5908-7-102

Cite this article as: Urquhart et al:: How do surgeons decide to refer patients for adjuvant cancer treatment? Protocol for a qualitative study. Implementation Science 2012 7:102.

\section{Submit your next manuscript to BioMed Central and take full advantage of:}

- Convenient online submission

- Thorough peer review

- No space constraints or color figure charges

- Immediate publication on acceptance

- Inclusion in PubMed, CAS, Scopus and Google Scholar

- Research which is freely available for redistribution 